\title{
To count or not to count: the effect of instructions on expecting a break in timing
}

\author{
Rémi Gaudreault • Claudette Fortin
}

Published online: 27 December 2012

(C) Psychonomic Society, Inc. 2012

\begin{abstract}
When a break is expected during a time interval production, longer intervals are produced as the break occurs later during the interval. This effect of break location was interpreted as a result of distraction related to break expectancy in previous studies. In the present study, the influence of target duration and of instructions about chronometric counting strategies on the break location effect was examined. Using a strategy such as chronometric counting enhances the reliability of temporal processing, typically in terms of reduced variability, and could influence how timing is affected by break expectancy, especially when relatively long target durations are used. In two experiments, results show that time productions lengthened with increasing value of break location at various target durations and that variability was greater in the no-counting than in the counting instruction condition. More important, the break location effect was stronger in the no-counting than in the counting instruction condition. We conclude that chronometric counting orients attention toward timing processes, making them less likely to be disrupted by concurrent nontemporal processes.
\end{abstract}

Keywords Temporal processing - Attention: divided attention and inattention - Grouping and segmentation

The perceived duration of a period of time varies depending on the orientation of our attention: Time seems longer if our attention is oriented to its passage and shorter when we are absorbed in some concurrent activity. This interference effect, one of the most consistent effects in the timing literature (Brown, 1997, 2008b), has contributed significantly to

\footnotetext{
R. Gaudreault $(\bowtie) \cdot$ C. Fortin

École de psychologie, Université Laval,

Québec, QC, Canada G1V 0A6

e-mail: remi.gaudreault@psy.ulaval.ca
}

establishing the assumption that attention plays a critical role in time estimation in humans. Numerous studies, using a dual-task paradigm, have confirmed the imperative role of attention in timing under prospective conditions, when participants know before the beginning of the task that a temporal judgment will be required. When participants are performing temporal and nontemporal tasks simultaneously (e.g., perceptual, mental arithmetic, motor tracking), the perceived duration shortens with increasing difficulty or duration of nontemporal processing (Brown, 1985, 1998, 2006, 2010; Champagne \& Fortin, 2008; Field \& Groeger, 2004; Fortin, Champagne, \& Poirier, 2007; Fortin \& Rousseau, 1998; Macar, 2002; Macar, Grondin, \& Casini, 1994; Rammsayer \& Ulrich, 2005; Thomas \& Weaver, 1975; Zakay, Nitzan, \& Glicksohn, 1983). Temporal underestimation can be accounted for by an attention allocation model (for recent reviews, see Brown, 2008b, 2010). According to this interpretation, a given duration is estimated through an accumulation of temporal information or temporal cues in a cognitive timer, and this process requires attention (e.g., Hicks, Miller, \& Kinsbourne, 1976; Lejeune, 1998; Meck, 1984; Zakay \& Block, 1996). In a dual-task paradigm, attentional resources are shared between temporal and nontemporal processing, and thus, a smaller amount of resources is allocated to timing than in a single-task paradigm. This competition for resources is assumed to lead to disruption or interruption in the temporal accumulation process and, consequently, to shorter perceived durations.

In order to study the effect of an interruption independently from the effect of concurrent processing, Fortin and Massé (2000) modified the dual-task paradigm by replacing the nontemporal task with an empty break, a systematic interruption in time interval production. In this task, participants began a trial by pressing a key, which triggered a tone presentation, and ended the interval production with a second keystroke. In experimental trials, there was a silent 
break in tone presentation, during which the participants were asked to interrupt timing. After the break, the tone presentation resumed, and the interval production was terminated when it was judged that the sum of pre- and postbreak intervals corresponded to the target duration. In that study, varying the location of the break in time production, which corresponded to the duration preceding the signal of break onset, allowed the authors to evaluate the effect of expecting a break in timing. ${ }^{1}$ The main result was a linear increase of produced intervals with increasing prebreak durations. This effect, named the break location effect, was interpreted as a result of attentional time-sharing between accumulation of temporal information and monitoring the source of the break signal. Because the participants must interrupt timing during the break and that interrupting of timing as soon as the break signal occurs is critical for accurate timing performance, they would specifically allocate attention to monitor the source from which the onset of the auditory break signal will be perceived. This would result in attention shifting between an internal source of temporal information and the auditory channel from which the break signal will be processed.

According to internal clock timing models such as the temporal information processing (TIP) model (based on the scalar expectancy theory; see Church, 1984; Gibbon, 1977, 1991; Gibbon, Church, \& Meck, 1984), producing a target time interval involves transferring temporal information (pulses) from a pacemaker to an accumulator until a criterion number of pulses is reached. This transfer is under the control of attention via a switch between the pacemaker and the accumulator, which can be closed, allowing pulse transfer when attention is directed to time, or opened, interrupting the accumulation process when attention is diverted from time (Meck, 1984; Rousseau, Picard, \& Pitre, 1984; Zakay \& Block, 1996). In this view, the state of the switch may be modified during two periods in the break paradigm. First, in accordance with instructions, it would be in an open state during the break, interrupting completely the accumulation process. Second, before the break, shifts of attention between pulse accumulation and monitoring the source of the break signal would make the switch flicker from a closed to an open state and, thus, would cause some relative loss of pulses during the prebreak period. Increasing the duration of this period results in a greater loss of temporal information and, consequently, in longer time productions, because the

\footnotetext{
${ }^{1}$ Note that the level of break expectancy, defined as the inverse of uncertainty, has been manipulated in previous studies by including cued and uncued trials without a break among trials with a break (Fortin \& Massé, 2000), by varying the proportion of trials including a break and not including a break, with and without cues (Fortin, 2003), and by varying the number of possible break locations (Blier, Fortin, \& Gaudreault, 2008). In the present study, only the duration of the break expectancy was manipulated.
}

target criterion will be reached later (Fortin, 2003; Fortin \& Massé, 2000). In an attention-sharing context, the slope of functions relating produced time intervals to the duration of break expectancy is interpreted as an index of the rate in pulse accumulation, since it represents the relative loss in pulse accumulation during the prebreak period. The slope is therefore indicative of the strength of the break location effect (Fortin, 2003). A critical test of the attentional interpretation of the break location effect was performed when trials with no breaks were mixed with trials with breaks in blocks of trials: The longest productions were produced when a break was expected throughout the interval production but did not occur (Fortin, 2003; Fortin \& Massé, 2000; Fortin \& Tremblay, 2006).

The break location effect has been observed with various timing tasks, such as production of well-practiced brief time intervals (Bherer, Desjardins, \& Fortin, 2007; Fortin, 2003; Fortin, Bédard, \& Champagne, 2005; Fortin \& Massé, 2000), temporal discrimination (Fortin \& Tremblay, 2006; Tremblay \& Fortin, 2003), and time reproduction in a peakinterval procedure (Fortin et al., 2009). Similar effects were found when the location of intervening stimuli was manipulated in an interval to be estimated, and an interpretation in terms of attention sharing was also suggested (Buffardi, 1971; Burle \& Casini, 2001; Casini \& Macar, 1997; Champagne \& Fortin, 2008; Gaudreault, Fortin, \& Macar, 2010; Macar, 2002; Rakitin, 2005; Rousseau et al., 1984). Although dual-task studies on the role of attention in timing covered a large range of durations (e.g., Fortin \& Couture, 2002; Hemmes, Brown, \& Kladopoulos, 2004; Macar, 2002), in most studies using the break paradigm, target durations around $2 \mathrm{~s}$ were used and did not vary within experiments. To our knowledge, only two studies have tested the break location effect using various durations within a single experiment (Fortin et al., 2009; Gaudreault et al., 2010). Fortin et al. (2009) contrasted three different target durations $(2.4,3.2$, and $4.0 \mathrm{~s})$ using a peak-interval procedure with breaks; the location effect was observed at all three target durations. In a time reproduction task, Gaudreault et al. observed the effect with both 2.5- and 4.5-s target durations in two experiments, although the effect was stronger at the shortest duration in one experiment. Evidence for the generality of the break location effect beyond $2 \mathrm{~s}$ remains, therefore, quite limited.

The influence of objective durations has been a key issue in the development of timing models, since they appear to influence performance (e.g., Allan \& Kristofferson, 1974; Fraisse, 1984; Michon, 1985; Zakay, 1990). Although some researchers refer to a single central mechanism to account for results in timing a wide range of durations, a significant number of studies suggest that at least two different timing mechanisms are needed to account for results with large duration ranges (e.g., Church, 1997; Crystal, 2003; Lewis 
\& Miall, 2003; Rammsayer \& Lima, 1991; Rammsayer \& Ulrich, 2005; see Grondin, 2001, for a review). Consequently, testing effects observed in timing studies with different ranges of durations is essential in order to truly understand the observed phenomena. This is one aspect that the present study investigated.

A well-known example challenging the idea of a unique model of timing concerns the violation of Weber's law (constant coefficient of variation, $C V=S D / M$, across different target durations) with durations longer than $2 \mathrm{~s}$. Several studies have reported that while $C V \mathrm{~s}$ remained mostly constant with durations from 0.5 to $2.0 \mathrm{~s}$, they increased with longer durations (e.g., Allan \& Kristofferson, 1974; Getty, 1975; Woodrow, 1930; see Wearden \& Lejeune, 2008, for a recent review). One way to prevent this increase in Weber's fraction is to allow participants to use a chronometric counting strategy. Ironically, one reason for using short durations (around or below $2 \mathrm{~s}$ ) in timing studies is actually to prevent the use of chronometric counting in order to study "uncontaminated" or "pure" timing processes (Fetterman \& Killeen, 1990; Kladopoulos, Hemmes, \& Brown, 2004; Rakitin et al., 1998; Wearden, Denovan, Fakhri, \& Haworth, 1997). Nevertheless, when asked to estimate an interval in the seconds-to-minutes range, most people spontaneously tend to use a chronometric counting strategy unless something prevents them from doing so (Fetterman \& Killeen, 1990; Fraisse, 1963; Getty, 1976; Gilliland \& Martin, 1940; Killeen \& Weiss, 1987). This strategy refers to verbally subdividing a single long interval into a consecutive series of shorter equal subintervals. In other words, it consists in estimation of basic time units (counts) to reach a total number corresponding to the target time interval (Kladopoulos et al., 2004; Wearden, 1991). Chronometric counting improves accuracy in temporal estimates - typically, in terms of reduced variability (Fetterman \& Killeen, 1990; Getty, 1976; Gilliland \& Martin, 1940; Grondin, 1992; Grondin, Meilleur Wells, \& Lachance, 1999; Grondin, Ouellet, \& Roussel, 2004; Hicks \& Allen, 1979; Hinton, Harrington, Binder, Durgerian, \& Rao, 2004; Hinton \& Rao, 2004; Kladopoulos et al., 2004; Petrusic, 1984, 2002; Rakitin et al., 1998; Wearden et al., 1997).

This reduction of variability suggests that timing with and without counting display different psychophysical properties. Violation of the scalar timing property would result from subdividing time interval into fixed subintervals when the sum of the variances of these subintervals is less than the variance of the produced interval taken as a whole. Therefore, using a counting strategy makes produced intervals less variable from trial to trial and eliminates the increase of variability in temporal representation with increasing target duration (Grondin et al., 1999; Grondin et al., 2004; Hinton et al., 2004; Hinton \& Rao, 2004; Killeen \& Weiss, 1987; Rattat \& Droit-Volet, 2012). However, although performance with counting does not globally conform to the scalar timing property, intercount intervals themselves do obey Weber's law (Wearden, 1991; Wearden $\&$ McShane, 1988). This suggests that intercount duration is established by the same internal timing mechanism as in pure timing (Grondin, 2001; Hinton et al., 2004). One way to explain the reduced variability in timing supported by chronometric counting relies on the contribution of memory to the overall variance; remembering a number instead of an interval representation would generate less variability (Grondin et al., 2004; Rakitin et al., 1998).

Recently, Rattat and Droit-Volet (2012) contrasted three methods of suppressing spontaneous counting in a timing task: instructions not to count, articulatory suppression, and administration of an interfering task. They found that the three methods are efficient in preventing participants from using a counting strategy but that the interference method disrupted temporal performance to a greater extent than did both instructions not to count and articulatory suppression. The authors concluded that given its simplicity and efficiency, the best method was to instruct participants not to count. They also suggested testing the effect of these instructions in a context of multiple duration values, in order to verify whether the scalar property would hold under these conditions.

To summarize, studies in human timing on the break location effect mostly have used target durations around $2 \mathrm{~s}$. One reason for restricting the range of tested durations was to prevent the use of chronometric counting in order to support timing. The present study aims at extending this investigation to a wider range of objective target durations. However, in human timing research using durations in the seconds-to-minutes range, participants tend to use counting strategies spontaneously, which influences timing performance (e.g., Fetterman \& Killeen, 1990; Getty, 1976; Gilliland \& Martin, 1940; Rattat \& Droit-Volet, 2012). Thus, the objective of the present study was twofold: to evaluate the effect of varying break location in intervals beyond the critical 2-s target duration and to test the impact of instructions on using a chronometric counting strategy in time production with a break.

In the following experiments, a time production task with a break similar to that developed in Fortin and Massé (2000) was adopted. In Experiment 1, there were three target interval durations: 2,4 , and $6 \mathrm{~s}$. The location and the duration of the break were manipulated from trial to trial. The break could occur after $37.5 \%, 50.0 \%$, or $62.5 \%$ of the target interval had elapsed and lasted 1,2 , or $3 \mathrm{~s}$. Two instruction conditions were compared: In one group, participants were instructed to use a chronometric counting strategy to support timing, and in another group, instructions prohibiting any self-generated counting strategy or other rhythm-related strategy were provided. According to the attention-sharing interpretation, the critical period for the development of the 
break location effect is the period preceding the break. This hypothesis was tested in conjunction with the impact of instructions about counting in Experiment 2, by using fixed prebreak durations instead of prebreak durations proportional to target durations, as in Experiment 1.

\section{Experiment 1}

Method

\section{Participants}

Twenty-four participants (17 women), between 20 and 48 years old $(M=26.83, S D=8.50)$, received a small honorarium ( $\$ 5 \mathrm{CAD}$ per session) to take part in the experiment. They were all adult volunteers, mostly undergraduate and graduate university students recruited through advertisement at Laval University. All participants were naïve as to the purpose and hypotheses of the experiment and had never participated in timing experiments previously.

\section{Apparatus and stimuli}

Participants were all tested individually in a sound-attenuated test chamber dimly lighted with a $40-\mathrm{W}$ bulb. They were seated in front of a computer screen, at a distance of about $70 \mathrm{~cm}$ from the monitor screen (VGA, $20 \times 27 \mathrm{~cm}$ ), with the right hand resting on the numerical keyboard of the computer. An MS-Windows-compatible computer running E-Prime 1.1 software controlled stimulus and feedback presentation, as well as data recording. Instructions, feedback, and the fixation point were displayed in the middle of the screen in white on a black background, and the size of each character was equivalent to 14 characters per inch. The auditory stimulus $(550 \mathrm{~Hz}$ and $60 \mathrm{~dB}$ ) was created with the Sound Forge 7.0 software and was emitted through two stereo speakers, each speaker being at a distance of $10 \mathrm{~cm}$, on each side of the screen. The "0" key on the numerical keyboard of the computer served to produce the time intervals. Time productions were recorded to the nearest millisecond.

\section{Procedure}

Participants were randomly divided into two groups of 12 , one assigned to the counting instruction (CI) condition and the other assigned to the no-counting instruction $(\mathrm{N}-\mathrm{Cl})$ condition. In the CI condition, participants were instructed to use chronometric counting - that is, to count numbers to support their time estimation. They were free to count aloud or not and were advised to count rapidly without committing errors. In the N-CI condition, there were instructions forbidding the use of any explicit timing strategy, including counting and other rhythm- related means (e.g., finger or foot tapping, singing). These instructions were given before the first practice block and were repeated by the experimenter before each subsequent experimental session. They were also displayed on the computer screen during each interblock pause. At the end of each session, the participants were asked whether they had succeeded in following these instructions; all participants confirmed having followed the instructions in all sessions. In a postexperimental questionnaire, participants in the CI condition had to report the number of count units that, according to them, corresponded to the target duration; in other words, they had to give the cardinal number reached for each target duration. The experiment was divided into two sessions, one for each target interval duration. Each session consisted of three practice blocks (two with feedback and one without), followed by three experimental blocks with a break and one last block without a break. Each block contained 36 trials, and blocks were separated by a 20 -s pause. The sessions lasted between 25 and $45 \mathrm{~min}$.

Every trial began with an asterisk $(*)$ presented in the middle of the screen until the participant initiated the trial. The target interval (a 2-, 4-, or 6-s tone) was presented five times at the beginning of the session. The participants were asked to memorize this target interval, which they would later have to produce throughout the experimental session. The duration of the tone in formal units of time (seconds) was never mentioned. After the initial presentation, the participants produced the target interval (tone duration) in three practice blocks. Trials in the first two practice blocks were followed by a feedback, indicating whether the production was too short, too long, or correct, relative to the presented duration. A correct feedback was provided when the produced interval corresponded to the presented interval within a $10 \%$ temporal window. No feedback was provided in the third and final practice block. When displayed, the feedback was shown in the middle of the screen, immediately after the end of the time production. The feedback was displayed for $1.5 \mathrm{~s}$ and was followed by an asterisk $(*)$, which was shown until the participant initiated the next trial.

The participant began and ended the interval production by pressing the " 0 " key of the numerical keyboard twice. The first keystroke initiated a tone presentation, which ended with the second keystroke, when the participant terminated the interval production. On experimental trials, there was a temporary interruption in tone presentation during the interval production. The interruption started when $37.5 \%, 50.0 \%$, or $62.5 \%$ of the target interval had elapsed; these were the three possible values of break location. The break duration varied and could be 1,2, or $3 \mathrm{~s}$. Participants were informed that break location and duration would vary from trial to trial. They were asked to interrupt timing for the duration of the break and to continue their time production when the tone presentation resumed. No feedback was given during experimental trials. As on practice trials, an asterisk $(*)$ followed the second keystroke and remained in the middle of the screen until the participant 
started the following trial. The last block was identical to the practice block without feedback, and its function was to measure the stability of time productions relative to the target interval durations after the experimental blocks with a break.

Interval duration was varied across sessions, whereas break location and duration were varied across trials. Values of break location and duration were selected randomly on each trial, with the constraint that the number of trials was the same at each combination of factor levels. Each participant completed 12 trials in each of the nine combinations of factor levels for all three interval durations. The order in which target interval durations were presented was counterbalanced. When the two sessions were completed during the same day, they were separated by at least $1 \mathrm{~h}$. Sessions could be separated by a maximum delay of $48 \mathrm{~h}$.

\section{Results}

Means and standard deviations of time productions were calculated for each participant at each target duration. For trials with a break, mean time production was calculated by adding pre- and postbreak durations, without including break duration. Outliers, which corresponded to produced intervals longer or shorter than three standard deviations from the individual mean, were discarded. Overall, $0.71 \%$ of trials with a break and $0.66 \%$ of trials without a break were excluded.

Two measures from experimental trials with a break were analyzed: (1) standardized mean time production (mean time production/target interval duration) and (2) coefficient of variation $(\mathrm{CV}$; standard deviation divided by mean time production). Two split-plot ANOVAs with target interval duration $(2,4,6 \mathrm{~s})$, break location $(37.5 \%, 50.0 \%$, $62.5 \%$ of target duration), and break duration $(1,2,3 \mathrm{~s})$ as repeated measures and instruction condition $(\mathrm{CI}, \mathrm{N}-\mathrm{CI})$ as a nonrepeated measure were performed on standardized mean time productions and $C V \mathrm{~s}$ (complete results from the ANOVAs are presented in Appendix 1).

Standardized mean time productions and $C V \mathrm{~s}$ from trials without a break were also computed. Four split-plot ANOVAs with target interval duration as a repeated measure and instruction condition as a nonrepeated measure were performed on standardized mean time productions and $C V \mathrm{~s}$ from practice trials without feedback and trials of the last block (without a break). In addition, one-way ANOVAs were performed on cardinal numbers reported by the participants and on mean counting rate (cardinal number divided by mean time productions) in the CI condition, with target interval duration as an independent variable.

For each analysis, the level of significance for rejecting the null hypothesis was set to .05 . When the Mauchly test for sphericity was significant at an alpha value of .01, the $p$ value obtained with the Greenhouse-Geisser correction was used. For simplicity of presentation, we report uncorrected degrees of freedom. Finally, the Bonferroni adjustment was used for a posteriori tests.

\section{Time productions}

Figure 1 shows that standardized time productions were significantly longer in the N-CI than in the CI condition and that they increased with increasing value of target interval duration. More important, it shows that standardized time productions increased significantly with increasing value of break location but that this effect was influenced by the instruction condition (Fig. 1a) and the target duration (Fig. 1b). Results from the ANOVA confirmed that the interaction between instruction condition and break location was significant. Results from tests of simple main effects revealed that the break location effect was significant in both instruction conditions, $F(2,22)=9.91$, $p<.001, \eta_{\mathrm{p}}^{2}=.47$, and $F(2,22)=30.51, p<.001, \eta_{\mathrm{p}}^{2}=.74$, respectively, for the $\mathrm{CI}$ and $\mathrm{N}-\mathrm{CI}$ conditions. Thus, although the effect of location was significant with both instruction conditions, it was stronger in the N-CI condition. Polynomial contrasts revealed that the increase in produced intervals was linear,
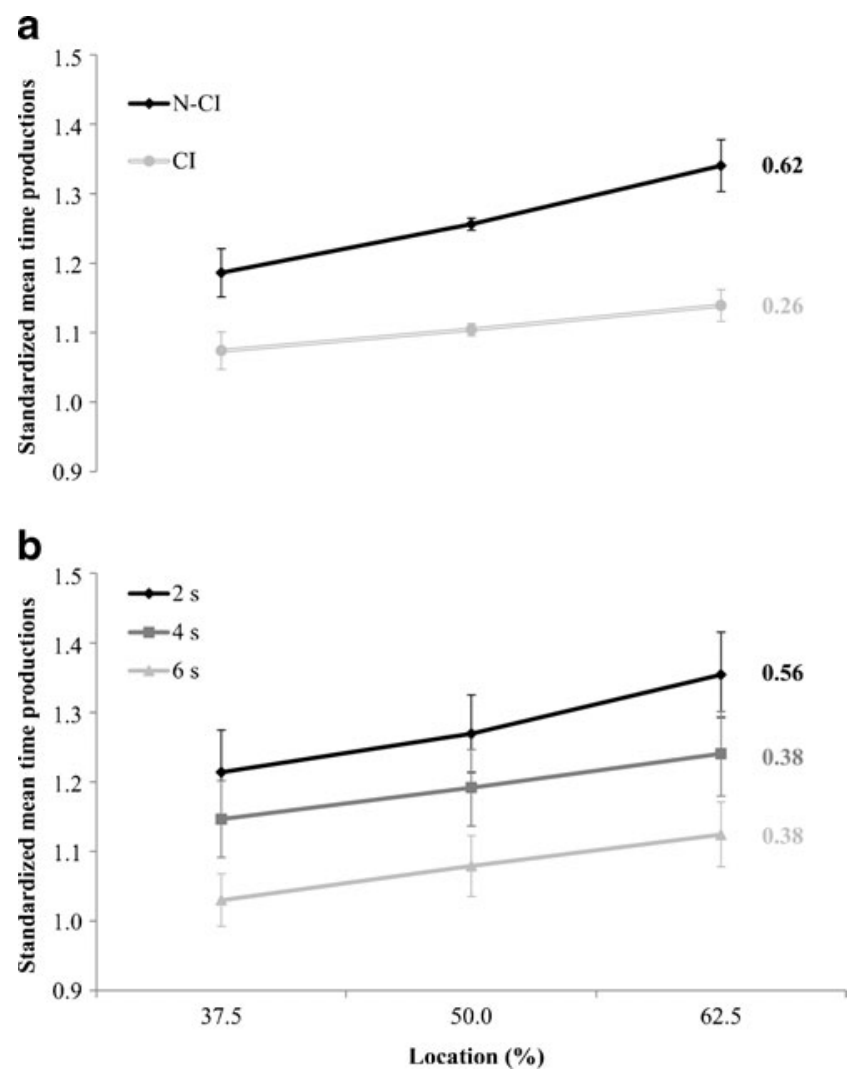

Fig. 1 Experiment 1: Standardized mean time productions as a function of break location for: a both instruction conditions (counting instruction $[\mathrm{CI}]$ and no-counting instruction $[\mathrm{N}-\mathrm{CI}]$ ) and $\mathbf{b}$ each target interval duration. Values of slopes of production functions are indicated next to each function (calculated from the best linear fit of the three points line). Error bars represent Cousineau-Morey $95 \%$ confidence intervals (see Morey, 2008) 
$F(1,11)=10.83, p<.01, \eta_{\mathrm{p}}^{2}=.49$, and $F(1,11)=31.94, p<$ $.001, \eta_{\mathrm{p}}^{2}=.74$, in the CI and N-CI conditions, respectively.

There was also a significant interaction between target interval duration and break location. Results from tests of simple main effects indicated that standardized time productions increased significantly with increasing value of break location at all target interval durations, $F(2,46)=37.03$, $p<.001, \eta_{\mathrm{p}}^{2}=.62, F(2,46)=21.00, p<.001, \eta_{\mathrm{p}}^{2}=.48$, and $F(2,46)=16.20, p<.001, \eta_{\mathrm{p}}^{2}=.41$, for the $2-, 4-$, and $6-\mathrm{s}$ intervals, respectively. Thus, although the effect of break location was significant at all target durations, the strength of the effect varied between the different values. Polynomial contrasts indicated that the increase in the production functions relative to break location was linear for the 2-s, $F(1$, $23)=40.62, p<.001, \eta_{\mathrm{p}}^{2}=.64$, the $4-\mathrm{s}, F(1,23)=23.46$, $p<.001, \eta_{\mathrm{p}}^{2}=.51$, and the 6-s, $F(1,23)=18.03, p<.001$, $\eta_{\mathrm{p}}^{2}=.44$, target interval durations.

Standardized mean time productions in blocks of trials without breaks are shown in Table 1. In the practice block without feedback, neither the effect of instruction condition, nor that of the target interval duration, nor the interaction between those factors was significant, all $F_{\mathrm{S}}<1$. In the last block, there was a significant effect of target interval duration, $F(2,44)=3.82, p=.03, \eta_{\mathrm{p}}^{2}=.15$. Standardized mean time productions were significantly longer for the 2-s than for the 6 -s interval ( $p=.036)$, but there was no significant difference between the 2 - and the 4-s intervals $(p=.362)$ and between the 4 - and the 6-s intervals $(p=.761)$. The effect of instruction condition and the interaction were not significant, both $F_{\mathrm{S}}<1$.

\section{Coefficients of variation}

Figure 2 shows $C V_{\mathrm{s}}$ at the three target interval durations in both instruction conditions. Results from the ANOVA indicated that $C V \mathrm{~s}$ were generally greater in the N-CI than in the CI condition. No other effects were significant in the analysis of experimental trials. Regarding blocks of trials without breaks (see Table 1), the effect of instruction condition and the interaction between instruction condition and target interval duration were significant both in the practice block without feedback, $F(1,22)=17.89, p<.001, \eta_{\mathrm{p}}^{2}=.45$, and $F(2,44)=$ 7.42, $p<.01, \eta_{\mathrm{p}}^{2}=.25$, respectively, and in the last block, $F(1$, $22)=8.33, p<.01, \eta_{\mathrm{p}}^{2}=.28$, and $F(2,44)=3.46, p<.05, \eta_{\mathrm{p}}^{2}=$ .14 , respectively. In the practice block without feedback, tests of simple main effects indicated that the effect of target interval duration was significant in the N-CI condition, $F(2,21)=5.39$, $p=.013, \eta_{\mathrm{p}}^{2}=.34$, but not in the CI condition, $F(2,21)=1.62$, $p=.221, \eta_{\mathrm{p}}^{2}=.13$. Pairwise comparisons revealed that $C V \mathrm{~s}$ were significantly smaller for the 2 -s interval than for the two other intervals, 4 and $6 \mathrm{~s}$ (both $p \mathrm{~s}<.05$ ) but that there was no significant difference between the 4- and the 6-s target intervals $(p=.145)$. In the last block, tests of simple main effects showed that the effect of target interval duration was not significant in both the N-CI condition, $F(2,21)=1.49, p=$ $.249, \eta_{\mathrm{p}}^{2}=.12$, and the CI condition, $F(2,21)=2.36, p=.119$, $\eta_{\mathrm{p}}^{2}=.18$. No other effect was significant (all $F_{\mathrm{S}}<1$ ).

\section{Chronometric counting}

Results from the ANOVA revealed that the mean cardinal number reported by the participants increased significantly with increasing target interval duration $(M=4.38, S D=1.82, M=$ 6.92, $S D=3.73$, and $M=10.33, S D=4.72$, for the $2-, 4-$, and 6 -s target intervals, respectively), $F(2,22)=33.26, p<.001$, $\eta_{\mathrm{p}}^{2}=.75$. Polynomial contrasts showed that the increase in cardinal numbers was linear, $F(1,11)=41.03, p<.001, \eta_{\mathrm{p}}^{2}=$ .79. The estimated mean counting rate did not differ between target durations $(M=1.80, S D=0.75, M=1.58, S D=0.73$, and $M=1.71, S D=0.70$ counts per second for the $2-, 4-$, and 6-s intervals, respectively), $F(2,22)=1.87, p=.18, \eta_{\mathrm{p}}^{2}=.15$.

\section{Discussion}

As in previous studies, produced intervals lengthened as a function of break location. More important, this lengthening was smaller in the CI than in the N-CI condition and smaller

Table 1 Experiment 1: Standardized mean time production (STP) and coefficient of variation $(\mathrm{CV})$ at the three target interval durations in trials without break

\begin{tabular}{|c|c|c|c|c|c|c|}
\hline \multirow[b]{2}{*}{ Condition } & \multicolumn{3}{|l|}{$\operatorname{STP}(S D)$} & \multicolumn{3}{|l|}{$C V(S D)$} \\
\hline & $2 \mathrm{~s}$ & $4 \mathrm{~s}$ & $6 \mathrm{~s}$ & $2 \mathrm{~s}$ & $4 \mathrm{~s}$ & $6 \mathrm{~s}$ \\
\hline \multicolumn{7}{|c|}{ Practice block } \\
\hline $\mathrm{CI}$ & $1.055(0.080)$ & $1.053(0.057)$ & $1.021(0.051)$ & $.077(.038)$ & $.068(.027)$ & $.057(.025)$ \\
\hline $\mathrm{N}-\mathrm{CI}$ & $1.089(0.093)$ & $1.054(0.200)$ & $1.063(0.159)$ & $.102(.026)$ & $.121(.036)$ & $.137(.057)$ \\
\hline \multicolumn{7}{|l|}{ Last block } \\
\hline CI & $1.113(0.142)$ & $1.052(0.140)$ & $0.992(0.070)$ & $.077(.036)$ & $.080(.084)$ & $.057(.035)$ \\
\hline $\mathrm{N}-\mathrm{CI}$ & $1.117(0.138)$ & $1.060(0.219)$ & $1.027(0.189)$ & $.105(.041)$ & $.114(.027)$ & $.136(.055)$ \\
\hline
\end{tabular}

Note. Practice block included trials without feedback only. $\mathrm{CI}=$ counting instruction, $\mathrm{N}-\mathrm{CI}=$ no-counting instruction. 


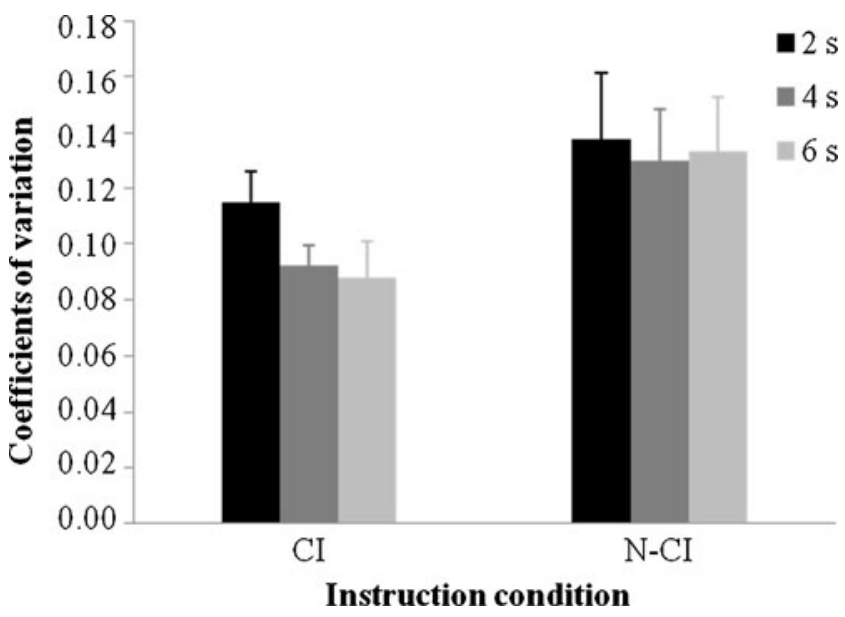

Fig. 2 Experiment 1: Coefficients of variation for the three target interval durations in both instruction conditions (counting instruction $[\mathrm{CI}]$ and no-counting instruction $[\mathrm{N}-\mathrm{CI}]$ )

for the 4- and 6-s durations than for the 2-s target duration. According to the attention-sharing interpretation of the location effect (Fortin, 2003), using a chronometric counting strategy to enhance precision in timing and using target durations longer than $2 \mathrm{~s}$ would have reduced the relative loss of temporal information during the prebreak period. More specifically, it would have reduced the number or duration of attention shifts during the accumulation process. This interpretation is discussed in greater detail in the "General Discussion" section.

Values of $C V \mathrm{~s}$ correspond to those that would be expected if the participants had used the reported strategies in the two groups and, thus, confirm that the instructions were followed. $C V_{\mathrm{s}}$ were greater in the $\mathrm{N}-\mathrm{CI}$ than in the $\mathrm{CI}$ condition and corresponded, respectively, to values observed when countingbased timing was used or not (Hinton \& Rao, 2004; see also Wearden, 1991). In both instruction conditions, $C V \mathrm{~s}$ were not significantly different across target durations in experimental blocks, which suggests conformity to Weber's law with these durations. In the N-CI condition of the practice block without feedback, however, $C V_{\mathrm{s}}$ were smaller for the 2-s than for the 4and 6-s intervals. This result, which shows a violation of Weber's law, is consistent with results observed in studies where the use of chronometric counting was prohibited (e.g., Getty, 1975).

Standardized produced intervals were longer in the N-CI than in the CI condition and longer for the 2-s than for the 6-s target duration. This may be due to the generally stronger break location effect, which contributes to lengthening produced intervals in the N-CI condition and in the 2-s target duration condition. Note that longer standardized time productions at the 2-s target duration were also observed in the last block (without a break). This could be seen as a shift of the internal criterion corresponding to the target interval, since overproduction was greater at the shortest target duration of the experimental blocks. On the other hand, this general effect of target interval duration could be explained, at least in part, by the Vierordt phenomenon, a tendency to underestimate longer intervals and overestimate shorter ones when target duration is varied across trials or blocks of trials (e.g., Woodrow, 1934; see Lejeune \& Wearden, 2009, for a recent review).

Finally, the mean cardinal number was higher at the longest target duration, showing that the participants used a correct chronometric counting strategy in order to support their time estimation and production. The absence of a significant difference between target interval durations on mean counting rate (cardinal number divided by mean time productions) was consistent with results obtained by Fetterman and Killeen (1990), results showing that although the privileged rate of counting varies from one participant to another, it remains constant and independent of the duration to be timed for most participants.

\section{Experiment 2}

According to its attentional interpretation, the break location effect involves only the period preceding the break, the period during which it is expected. This was shown in an experiment in which trials with no break were mixed with trials with a break. In that experiment, time productions increased linearly with increases in the duration for which a break was expected, whether or not a break actually occurred (Fortin \& Massé, 2000, Experiment 3). In Experiment 1 of the present study, break location values were proportional to the target duration; prebreak durations were therefore globally longer at the 6-s than at the 2-s target interval duration, and the break location effect was stronger at the shortest duration. Considering the interpretation of the break location effect in terms of attentional time-sharing between accumulation of temporal information and monitoring the source of the break signal, contrasting two target interval durations ( 2 and $6 \mathrm{~s}$ ) with identical prebreak durations $(750,1,000$, and $1,250 \mathrm{~ms})$ should abolish the interaction between target interval duration and break location. In order words, if the break location effect results specifically from processes taking place before the break onset, independently of the postbreak duration, a similar magnitude of the break location effect should be observed for different target interval durations with absolute prebreak durations. This was tested in Experiment 2.

Method

\section{Participants}

Twenty-four adult volunteers (17 women), between 18 and 57 years old $(M=25.79, S D=9.72)$, took part in this two- 
session experiment. All participants received an honorarium of $\$ 5(\mathrm{CDN})$ per session and were naïve as to the purpose and hypotheses of the experiment.

\section{Procedure}

All aspects of the procedure were similar to those in Experiment 1, with the exception that the values of break location were $750,1,000$, and $1,250 \mathrm{~ms}(37.5 \%, 50.0 \%$, and $62.5 \%$ of $2 \mathrm{~s}$ ) at both the 2- and 6-s target intervals.

\section{Results}

Values of break location being absolute and not relative to target durations in Experiment 2, the ANOVA on data from experimental trials was performed on mean time productions instead of standardized mean time productions. In order to provide an unbiased test of the interaction between target interval duration and break location, time productions used in the analysis, as well as values of break location, must be on the same scale. In Experiment 1, break location values were constant proportions of the target interval durations (prebreak durations being 37.5\%, $50.0 \%$, and $62.5 \%$ of the target interval duration). Consequently, time productions used in the analysis were relative to target duration as well (standardized time production). In contrast, in Experiment 2, values of break location were absolute (750, 1,000 , and $1,250 \mathrm{~ms}$, independently of the target duration). In this case, absolute values of time productions (in milliseconds) were therefore used in the analysis.

Means and standard deviations were calculated for each participant and each target duration. Outliers $( \pm 3 S D \mathrm{~s})$ were excluded, which represented $0.71 \%$ of all trials with a break and $0.61 \%$ of trials without a break. As in the previous experiment, two split-plot ANOVAs with three repeated measures (target interval duration, 2, $6 \mathrm{~s}$; break location, $750,1,000,1,250 \mathrm{~ms}$; break duration, 1, 2, $3 \mathrm{~s}$ ) and one nonrepeated measure (instruction condition: $\mathrm{CI}$ or $\mathrm{N}-\mathrm{CI}$ ) were carried out on time productions (unstandardized) and $C V \mathrm{~s}$ from experimental trials with a break (complete results from the ANOVA are presented in Appendix 2).

As in Experiment 1, standardized mean time productions and $C V \mathrm{~s}$ for practice trials without feedback and trials of the last block (without a break) were also computed, and ANOVAs with target interval duration as a repeated measure and instruction condition as a nonrepeated measure were performed on both dependent variables.

\section{Time productions}

As in Experiment 1, time productions increased with increasing prebreak duration. More importantly, with regard to the main objective of Experiment 2, this lengthening was similar for both the 2- and 6-s target intervals when the same three values of break location were used (see Fig. 3b). As in Experiment 1, however, the location effect interacted with the instruction condition factor (see Fig. 3a). Results from tests of simple main effects showed that the break location effect was significant in both the $\mathrm{CI}$ and $\mathrm{N}-\mathrm{CI}$ conditions but that it was stronger in the $\mathrm{N}-\mathrm{CI}$ condition, $F(2,22)=7.40, p=$ $.013, \eta_{\mathrm{p}}^{2}=.40$, and $F(2,22)=22.25, p<.001, \eta_{\mathrm{p}}^{2}=.67$, in the $\mathrm{CI}$ and N-CI conditions, respectively. Polynomial contrasts showed that the increase in time productions was linear, $F(1$, $11)=7.91, p=.017, \eta_{\mathrm{p}}^{2}=.42$, and $F(1,11)=31.05, p<.001$, $\eta_{\mathrm{p}}^{2}=.74$, in both the CI and the N-CI conditions, respectively.

There was a significant interaction between instruction condition, target interval duration, and break duration. Twoway interactions between target interval duration and break duration were tested at both levels of instruction condition. At a .025 level of significance (.05/2), the interaction between target interval duration and break duration was significant in the N-CI condition, $F(2,22)=7.01, p<.01, \eta_{\mathrm{p}}^{2}=$ .39 , but not in the CI condition, $F<1$. With a .0125 level of significance $(.025 / 2)$, results from tests of simple main effects in the $\mathrm{N}-\mathrm{CI}$ condition revealed that time productions did not differ significantly across break durations at the 2-s $(3,347,3,370,3,326 \mathrm{~ms}), F<1$, and the 6 -s $(6,681,6,802$,
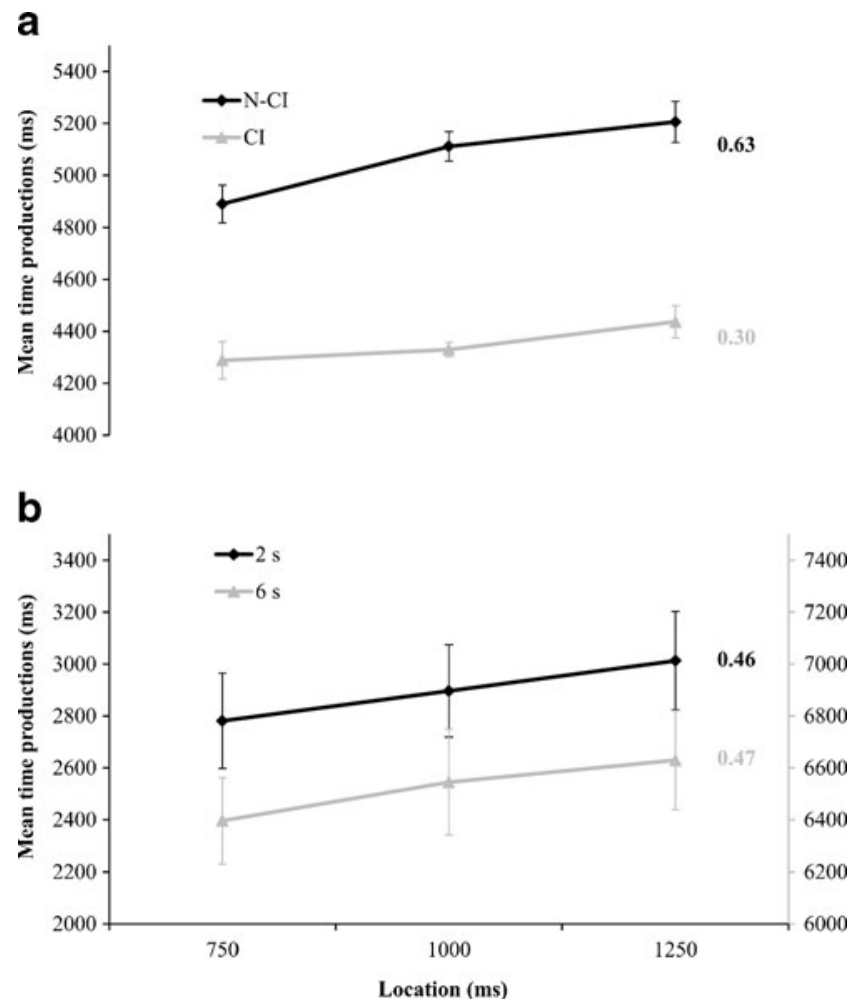

Fig. 3 Experiment 2: Mean time productions as a function of break location for a both instruction conditions (counting instruction $[\mathrm{CI}]$ and no-counting instruction $[\mathrm{N}-\mathrm{CI}]$ ) and $\mathbf{b}$ both target interval durations. Values of slopes of production functions are indicated next to each function 
$6,888 \mathrm{~ms}$ ) target interval durations, $F(2,22)=4.48, p=$ $.023, \eta_{\mathrm{p}}^{2}=.29$.

Time productions were generally longer in the N-CI than in the CI condition and were longer at the 6-s than at the 2-s target interval. In order to obtain a better comparison with the results of Experiment 1, an ANOVA on standardized time productions, with target interval duration ( 2 and $6 \mathrm{~s}$ ) as a repeated measure and instruction condition $(\mathrm{CI}$ and $\mathrm{N}-\mathrm{CI})$ as a nonrepeated measure, was performed. ${ }^{2}$ Mean standardized time productions were 1.22 and 1.04 at the 2- and the 6$\mathrm{s}$ target intervals, respectively, in the CI condition, and they were 1.67 and 1.13 at the 2- and the 6-s target intervals, respectively, in the N-CI condition. They were generally longer in the N-CI than in the CI condition, $F(1,22)=$ $11.64, p<.01, \eta_{\mathrm{p}}^{2}=.35$, and were longer at the 2-s than at the 6 -s target interval, $F(1,22)=67.05, p<.001, \eta_{\mathrm{p}}^{2}=$ .75. The interaction between the two factors was also significant, $F(1,22)=16.84, p<.001, \eta_{\mathrm{p}}^{2}=.43$. Tests of simple main effects indicated that standardized time productions were longer at the 2-s than at the 6-s interval both in the CI, $F(1,11)=8.33, p=.015, \eta_{\mathrm{p}}^{2}=.43$, and in the N-CI, $F(1,11)=75.68, p<.001, \eta_{\mathrm{p}}^{2}=.87$, conditions.

In the practice block without feedback, as in Experiment 1 , results from the ANOVA showed that neither the effect of instruction condition, nor that of the target interval duration, nor the interaction between those factors was significant, $F$ $(1,22)=1.37, p=.254, \eta_{\mathrm{p}}^{2}=.06, F(1,22)=2.25, p=.148$, $\eta_{\mathrm{p}}^{2}=.09$, and $F<1$, respectively. In the last block, the effect of target interval was significant, $F(1,22)=13.10, p<.01$, $\eta_{\mathrm{p}}^{2}=.37$, and interacted with the instruction conditions, $F$ $(1,22)=7.22, p=.013, \eta_{\mathrm{p}}^{2}=.25$. Tests of simple main effects showed that standardized time productions were longer at the 2-s than at the 6-s target interval in the N-CI condition, $F(1,11)=18.28, p<.01, \eta_{\mathrm{p}}^{2}=.62$, but not in the CI condition, $F<1$ (see Table 2).

\section{Coefficients of variation}

As in Experiment 1, $\mathrm{CV}$ s were greater in the $\mathrm{N}-\mathrm{CI}$ than in the CI condition (see Fig. 4). There was also a significant interaction between instruction condition and target interval duration. Tests of simple main effects showed that $C V_{\mathrm{s}}$ were greater at the 2-s than at the 6-s target interval in the CI condition, $F(1,11)=30.93, p<.001, \eta_{\mathrm{p}}^{2}=.74$, but there was no such difference in the $\mathrm{N}-\mathrm{CI}$ condition, $F<1$. No other effects were significant in the analysis of experimental trials.

$C V_{\mathrm{s}}$ in blocks of trials without breaks are shown in Table 1. In the practice block without feedback, results from

\footnotetext{
${ }^{2}$ Note that the break location factor was not included in this ANOVA, because location values were not relative to target interval duration in Experiment 2, preventing a comparison in terms of standardized time production.
}

Table 2 Experiment 2: Standardized mean time production (STP) and coefficient of variation $(\mathrm{CV})$ at the two target durations in trials without break

\begin{tabular}{llllll}
\hline & \multicolumn{2}{l}{$\mathrm{STP}(S D)$} & & \multicolumn{2}{l}{$C V(S D)$} \\
\cline { 2 - 3 } \cline { 5 - 6 } Condition & $2 \mathrm{~s}$ & $6 \mathrm{~s}$ & & $2 \mathrm{~s}$ & $6 \mathrm{~s}$ \\
\hline Practice block & & & & \\
$\mathrm{CI}$ & $1.051(0.117)$ & $1.021(0.054)$ & $.063(.038)$ & $.048(.036)$ \\
$\mathrm{N}-\mathrm{CI}$ & $1.162(0.312)$ & $1.069(0.193)$ & $.118(.058)$ & $.134(.050)$ \\
Last block & & & & \\
CI & $1.098(0.135)$ & $1.062(0.118)$ & $.050(.025)$ & $.038(.016)$ \\
N-CI & $1.352(0.365)$ & $1.109(0.297)$ & $.125(.048)$ & $.123(.053)$ \\
\hline
\end{tabular}

Note. Practice block included trials without feedback only. $\mathrm{CI}=$ counting instruction, $\mathrm{N}-\mathrm{CI}=$ no-counting instruction.

the ANOVA showed a significant effect of instruction condition, but it interacted with the target interval duration, $F(1$, $22)=16.62, p<.001, \eta_{\mathrm{p}}^{2}=.43$, and $F(1,22)=4.50, p=$ $.045, \eta_{\mathrm{p}}^{2}=.17$, respectively. Tests of simple main effects indicated that $C V \mathrm{~s}$ were significantly greater in the $\mathrm{N}-\mathrm{CI}$ than in the $\mathrm{CI}$ condition at both target interval durations, $F$ $(1,22)=7.64, p=.011, \eta_{\mathrm{p}}^{2}=.26$, and $F(1,22)=23.72, p<$ $.001 \eta_{\mathrm{p}}^{2}=.52$, respectively. Thus, although the effect of instruction condition was significant with both the 2- and the 6-s target intervals, it was stronger at the longest duration. In the last block, $C V \mathrm{~s}$ were greater in the N-CI than in the CI condition, $F(1,22)=35.99, p<.001, \eta_{\mathrm{p}}^{2}=.62$. The effect of target interval duration and the interaction were not significant (both $F \mathrm{~s}<1$ ).

\section{Discussion}

The aim of Experiment 2 was to test whether the interaction between target interval duration and break location found in

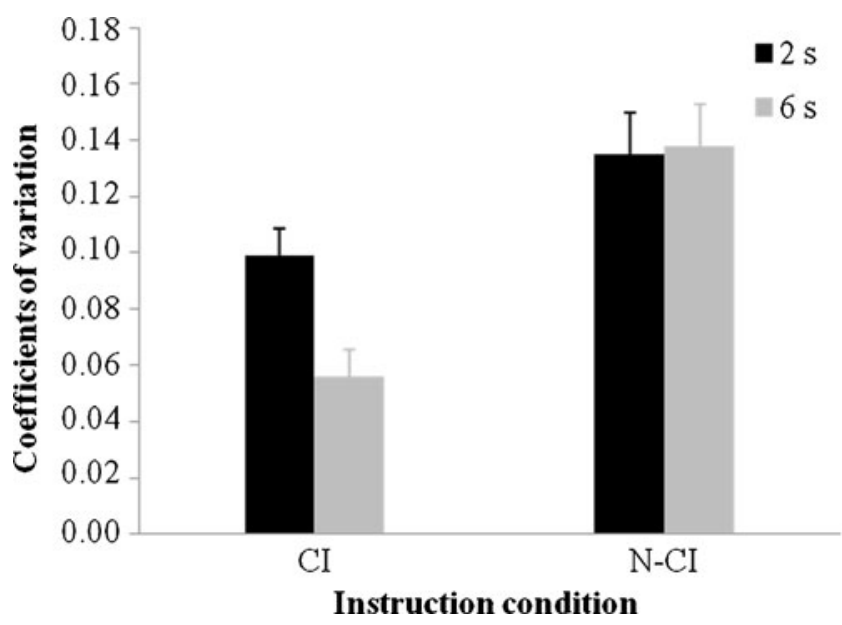

Fig. 4 Experiment 2: Coefficients of variation for the three target interval durations in both instruction conditions (counting instruction $[\mathrm{CI}]$ and no-counting instruction $[\mathrm{N}-\mathrm{CI}]$ ) 
Experiment 1 would be found with identical prebreak values at both target durations. A clear answer was provided by the results of the present experiment: Identical prebreak values led to similar break location effects at the 2- and 6-s target intervals, supporting the idea that the break location effect results from processes taking place before the break onset.

As in Experiment 1, the location effect was stronger in the N-CI than in the $\mathrm{CI}$ condition, and $C V \mathrm{~S}$ were greater in the $\mathrm{N}-\mathrm{CI}$ than in the $\mathrm{CI}$ condition. $C V \mathrm{~s}$ were also greater at the 2-s than at the 6-s target interval in the CI condition, however, whereas there was no effect of target interval in Experiment 1. This result, which shows a violation of Weber's law, is consistent with results observed in studies where chronometric counting is allowed (e.g., Kladopoulos, Brown, Hemmes, \& Cabeza de Vaca, 1998).

Time productions were longer at the 6-s than at the 2-s target interval. Besides, results from the analysis performed on standardized mean time production indicated that overproduction was, as in Experiment 1, generally greater with the 2-s than with the 6-s interval and greater in the N-CI than in the CI condition.

\section{General discussion}

In human timing studies, the interference effect was observed with the dual-task paradigm using various target durations to be estimated, which led researchers in the field to state that attention is involved in timing across a wide range of durations (Brown, 2008b, 2010). Varying location of tasks or of interruptions in timing also supported attentional models in human timing, but the range of durations tested in those studies was quite limited. In experiments on timing with breaks, this constraint aimed mainly at preventing participants from counting. The present study tested the generality of the break location effect across a wider range of durations, while manipulating instructions about the use of a chronometric counting strategy.

The lengthening of produced intervals with increasing values of prebreak duration was observed similarly in both experiments, and the increase in produced intervals was linear for all durations. This finding strengthens the interpretation of the location effect in terms of attention shifts between accumulating temporal information and monitoring for the break signal before its occurrence (Fortin, 2003; Fortin \& Massé, 2000; Rousseau et al., 1984). The results of the present study suggest further that the mechanisms involved in the break location effect take place in producing intervals as long as $6 \mathrm{~s}$. More specifically, according to an internal-clock model of timing (Gibbon et al., 1984; Zakay \& Block, 1996), which includes an attention-controlled flickering switch (Lejeune, 1998, 2000; Meck, 1984), attention shifts from the accumulation process to monitor the interruption signal would cause the opening of the switch and, therefore, some loss of temporal information. When the interruption signal occurs later, the monitoring period lasts longer, and the number of attention shifts is higher. This would lead to a greater loss of temporal information, resulting in longer produced intervals. Generalizing the location effect at longer durations is consistent with the linearity of the production functions, relative to break location, and suggests that shifts of attention are regularly distributed during the monitoring period. However, the magnitude of the break location effect was smaller with longer mean prebreak durations, suggesting that the relative loss of temporal information was less important with longer prebreak durations. This result is consistent with those observed in a previous study by Gaudreault et al. (2010). The authors suggested that this interaction between target interval duration and the location effect may be seen as a consequence of the Vierordt phenomenon. That is, underestimation of longer target durations would make underestimation related to time-sharing during the prebreak period relatively less important (Gaudreault et al., 2010). An alternative explanation would be that with the 4- and 6-s target durations, a smaller proportion of the prebreak interval would be devoted to nontemporal processing, because participants would benefit from time-sharing skills only with prebreak durations longer than 750, 1,000, and 1,250 ms. In the context of the interference effect, integration of the two tasks, coordination of the flow of information, and corrections or adjustments of temporal judgments in order to compensate for disruptions in attention to time are examples of time-sharing skills (Brown, 2008a).

When the participants were allowed to count, overall variability in timing was clearly reduced. This effect was present in both experiments of the present study, at all target durations. More important, in the CI condition, the impact of varying break location on produced intervals was also reduced. According to its interpretation within an internal clock framework, a weaker but linear location effect in the CI condition, relative to the N-CI condition, suggests that shifts of attention would be fewer or shorter but similarly distributed during the prebreak period. As a result, in comparison with a pure timing condition, a greater proportion of attention would be allocated to timing than to monitoring when the use of chronometric counting was allowed.

How would counting influence the allocation of attention? A straightforward interpretation is that counting serves as a periodic "reminder," which reorients attentional resources toward the accumulation process. A complementary interpretation would be that, by reducing variability in timing during the prebreak period, counting would decrease the 
level of temporal uncertainty about the possible moments of break occurrence. Consequently, the participants would learn that the break is more likely to occur after a few possible count numbers (e.g., after 4, 8, or 12 counts) and, thus, would prepare to interrupt timing only around those specific moments. Attention would be oriented toward monitoring the source of the break signal around three specific moments so that, overall, more resources would be available for accumulating temporal information. In other words, the total duration spent in attention sharing before the break would be shorter. Therefore, less temporal information would be lost because of break expectancy-hence, a weaker break location effect.

The results of the present study acknowledge the relationship between timing and chronometric counting. In fact, although the break location effect was weaker when participants were instructed to count, it was still present and significant. This suggests that like timing, chronometric counting would be vulnerable to interference in a shared attention situation, presumably because producing count units involves timing between counts, which, in turn, requires an internal timing mechanism (Grondin, 2001; Hinton et al., 2004; Wearden, 1991). Attention shifts between counts would cause some loss of pulses, which would lengthen the duration between the counts. Ultimately, this would decrease the count number during the prebreak period and, consequently, postpone the time when the number associated with the target duration is reached. Although this hypothesis was not directly tested in the present study, it could be further examined in an experiment requiring participants to repeatedly press a computer key as they count in order to record the time between counts (see Wearden, 1991, for an example).

Meck and colleagues proposed an integrated mode control model, which is basically an extension of the TIP model with a mode switch that can operate in two modes, one used to time and the other to count (Meck, 1997; Meck \& Church, 1983; Meck, Church, \& Gibbon, 1985). Consistent with this model, timing and counting could rely on the same central timing mechanism, which requires attention (e.g., Meck, 1984; Zakay \& Block, 1996). In the same way, Killeen (1992) noted that his analysis of the effectiveness of counting strategies (see Killeen \& Weiss, 1987) was recursive; the pacemaker of his pacemakercounter system being simply a faster pacemaker-counter system. In addition, data from neuroimaging studies support this idea that counting and timing may use the same internal clock as their source of elementary substrate. For example, results from a study by Hinton et al. (2004) suggested that in addition to areas associated with internal speech (Broca's area, primary motor cortex in the mouth region, and right cerebellum), counting activated structures associated with reproducing intervals in the range of several hundred milliseconds to several seconds (putamen, supplementary motor area, and cingulate motor area). Besides, referring to the striatal beat-frequency model of Buhusi and Meck (2005), Penney and Vaitilingam (2008) suggested that both counting and timing emerge from activity in thalamo-cortical-striatal loops that include the basal ganglia, the prefrontal cortex, and the posterior parietal cortex. In this view, observing the break location effect in both experimental conditions in the present study is consistent with a mode control model of counting and timing in which the same neural circuitry is used to process time and numbers in chronometric counting.

In the present study, the systematic differences observed in the counting and no-counting instruction conditions show that mere instructions, with no other interfering task whose aim is to prevent chronometric counting, may be sufficient to control the use of counting strategies in timing experiments. This finding is especially interesting given that asking participants to perform interfering tasks, which are often employed to prevent counting in human timing experiments, may itself be distracting and introduce extraneous variables that can obscure effects specifically related to timing mechanisms (Rattat \& Droit-Volet, 2012). Moreover, the results of the present study show that chronometric counting could influence the location effect even with prebreak durations as short as $750,1,000$, and $1,250 \mathrm{~ms}$. This suggests that using short durations (around $2 \mathrm{~s}$ or less) may not be sufficient to prevent the influence of chronometric counting on results in studies on timing with breaks. More generally, the present results emphasize the importance of including specific instructions prohibiting the use of chronometric counting when studying timing mechanisms.

To conclude, the present study confirmed the reliability of the location effect and showed that it can be generalized to different target durations. These results consolidated and allowed us to develop the attentional interpretation of this effect, not only by showing interference from expecting an interruption in timing to a wider range of durations, but also by revealing that counting-like strategies can modulate the effect, possibly by focusing attention on timing processes at specific moments during the prebreak period. Finally, by showing effects of varying break location when counting is deliberately used in order to support timing, this study reveals that chronometric counting is vulnerable to attentional manipulations, supporting the theoretical hypothesis according to which chronometric counting and timing rely on the same internal source of temporal information.

Acknowledgements This work was supported by a grant to Claudette Fortin from the Natural Sciences and Engineering Research Council of Canada (NSERC). 


\section{Appendix 1}

Table 3 Experiment 1: Results from ANOVAs on standardized time production (STP) and coefficient of variation (CV)

\begin{tabular}{|c|c|c|c|c|c|c|c|}
\hline \multirow[b]{2}{*}{ Source } & \multirow[b]{2}{*}{$d f$} & \multicolumn{6}{|c|}{$F$ value, mean square error $(M S E)$ and effect size $\left(\eta_{\mathrm{p}}^{2}\right)$} \\
\hline & & $F$ & STP $M S E$ & $\eta_{\mathrm{p}}^{2}$ & $F$ & $C V M S E$ & $\eta_{\mathrm{p}}^{2}$ \\
\hline Condition (C) & 1,22 & $4.66^{*}$ & .836 & .18 & $4.18^{*}$ & .049 & .16 \\
\hline Target duration (TD) & 2,44 & $10.64^{+}$ & .208 & .33 & 2.47 & .007 & .10 \\
\hline $\mathrm{TD} \times \mathrm{C}$ & 2,44 & 1.00 & .208 & .04 & 1.01 & .007 & .04 \\
\hline Break location (BL) & 2,44 & $37.31^{+}$ & .031 & .63 & 0.69 & .002 & .03 \\
\hline $\mathrm{BL} \times \mathrm{C}$ & 2,44 & $6.19^{+}$ & .031 & .22 & 1.27 & .002 & .05 \\
\hline Break duration (BD) & 2,44 & 0.49 & .037 & .02 & 2.79 & .001 & .11 \\
\hline $\mathrm{BD} \times \mathrm{C}$ & 2,44 & $<.01$ & .037 & $<.01$ & 2.55 & .001 & .10 \\
\hline $\mathrm{TD} \times \mathrm{BL}$ & 4,88 & $4.89^{+}$ & .005 & .18 & 1.43 & .002 & .06 \\
\hline $\mathrm{TD} \times \mathrm{BL} \times \mathrm{C}$ & 4,88 & 0.27 & .005 & .01 & 0.79 & .002 & .03 \\
\hline $\mathrm{TD} \times \mathrm{BD}$ & 4,88 & 0.67 & .015 & .03 & 0.35 & .001 & .02 \\
\hline $\mathrm{TD} \times \mathrm{BD} \times \mathrm{C}$ & 4,88 & 0.19 & .015 & .01 & 0.67 & .001 & .03 \\
\hline $\mathrm{BL} \times \mathrm{BD}$ & 4,88 & 0.16 & .001 & .01 & 0.32 & .001 & .01 \\
\hline $\mathrm{BL} \times \mathrm{BD} \times \mathrm{C}$ & 4,88 & 1.29 & .001 & .06 & 0.80 & .001 & .04 \\
\hline $\mathrm{TD} \times \mathrm{BL} \times \mathrm{BD}$ & 8,176 & 0.48 & .004 & .02 & 0.89 & .001 & .04 \\
\hline $\mathrm{TD} \times \mathrm{BL} \times \mathrm{BD} \times \mathrm{C}$ & 8,176 & 0.49 & .004 & .02 & 1.73 & .001 & .07 \\
\hline
\end{tabular}

${ }^{*} p \leq .05$

${ }^{+} p \leq .01$

\section{Appendix 2}

Table 4 Experiment 2: Results from ANOVAs on time production (TP) and coefficient of variation (CV)

\begin{tabular}{|c|c|c|c|c|c|c|c|}
\hline \multirow[b]{2}{*}{ Source } & \multirow[b]{2}{*}{$d f$} & \multicolumn{6}{|c|}{$F$ value, mean square error $(M S E)$ and effect size $\left(\eta_{\mathrm{p}}^{2}\right)$} \\
\hline & & $F$ & TP $M S E$ & $\eta_{\mathrm{p}}^{2}$ & $F$ & $C V M S E$ & $\eta_{\mathrm{p}}^{2}$ \\
\hline Condition (C) & 1,22 & $6.11^{*}$ & $9.11 \mathrm{E} 6$ & .22 & $24.48^{+}$ & .019 & .53 \\
\hline Target duration (TD) & 1,22 & $404.1^{+}$ & $3.52 \mathrm{E} 6$ & .95 & 2.47 & .008 & .10 \\
\hline $\mathrm{TD} \times \mathrm{C}$ & 1,22 & 1.04 & $3.52 \mathrm{E} 6$ & .05 & $10.95^{+}$ & .008 & .33 \\
\hline Break location (BL) & 2,44 & $27.44^{+}$ & $7.12 \mathrm{E} 4$ & .56 & 0.35 & .001 & .02 \\
\hline $\mathrm{BL} \times \mathrm{C}$ & 2,44 & $5.12^{+}$ & 7.12E4 & .19 & 0.58 & .001 & .03 \\
\hline Break duration (BD) & 2,44 & 1.67 & $5.42 \mathrm{E} 4$ & .07 & 0.10 & .001 & .01 \\
\hline $\mathrm{BD} \times \mathrm{C}$ & 2,44 & 1.69 & $5.42 \mathrm{E} 4$ & .07 & 0.30 & .001 & .01 \\
\hline $\mathrm{TD} \times \mathrm{BL}$ & 2,44 & 0.34 & $3.67 \mathrm{E} 4$ & .02 & 0.56 & .001 & .03 \\
\hline $\mathrm{TD} \times \mathrm{BL} \times \mathrm{C}$ & 2,44 & 1.56 & $3.67 \mathrm{E} 4$ & .07 & 0.80 & .001 & .04 \\
\hline $\mathrm{TD} \times \mathrm{BD}$ & 2,44 & $7.17^{+}$ & $2.04 \mathrm{E} 4$ & .25 & 0.34 & .001 & .02 \\
\hline $\mathrm{TD} \times \mathrm{BD} \times \mathrm{C}$ & 2,44 & $4.57^{*}$ & $2.04 \mathrm{E} 4$ & .17 & 0.02 & .001 & $<.01$ \\
\hline $\mathrm{BL} \times \mathrm{BD}$ & 4,88 & 1.20 & $6.88 \mathrm{E} 4$ & .05 & 2.46 & .001 & .10 \\
\hline $\mathrm{BL} \times \mathrm{BD} \times \mathrm{C}$ & 4,88 & 0.75 & $6.88 \mathrm{E} 4$ & .03 & 1.88 & .001 & .08 \\
\hline $\mathrm{TD} \times \mathrm{BL} \times \mathrm{BD}$ & 4,88 & 0.76 & $8.40 \mathrm{E} 4$ & .03 & 0.68 & .001 & .03 \\
\hline $\mathrm{TD} \times \mathrm{BL} \times \mathrm{BD} \times \mathrm{C}$ & 4,88 & 0.74 & $8.40 \mathrm{E} 4$ & .03 & 0.96 & .001 & .04 \\
\hline
\end{tabular}




\section{References}

Allan, L. G., \& Kristofferson, A. B. (1974). Psychophysical theories of duration discrimination. Perception \& Psychophysics, 16, 26-34.

Bherer, L., Desjardins, S., \& Fortin, C. (2007). Age-related differences in timing with breaks. Psychology and Aging, 22, 398-403. doi: $10.1037 / 0882-7974.22 .2 .398$

Blier, M., Fortin, C. \& Gaudreault, R. (2008). Preparatory processes, uncertainty and timing. Poster presented at BBCS 18th annual meeting, London, Canada.

Brown, S. W. (1985). Time perception and attention: The effects of prospective versus retrospective paradigms and task demands on perceived duration. Perception \& Psychophysics, 38, 115-124.

Brown, S. W. (1997). Attentional resources in timing: Interference effects in concurrent temporal and nontemporal working memory tasks. Perception \& Psychophysics, 59, 1118-1140.

Brown, S. W. (1998). Automaticity versus timesharing in timing and tracking dual-task performance. Psychological Research/ Psychologische Forschung. Special Issue: Timing in perception and action, 61, 71-81. doi:10.1007/s004260050014

Brown, S. W. (2006). Timing and executive function: Bidirectional interference between concurrent temporal production and randomization tasks. Memory \& Cognition, 34, 1464-1471.

Brown, S. W. (2008a). The attenuation effect in timing: Counteracting dual-task interference with time judgment skill training. Perception, 37, 712-724

Brown, S. W. (2008b). Time and attention: Review of the Literature. In S. Grondin (Ed.), Psychology of time (pp. 111-138). Bingley, UK: Emerald.

Brown, S. W. (2010). Timing, resources, and interference: Attentional modulation of time perception. In K. C. Nobre \& J. T. Coull (Eds.), Attention and time (pp. 107-121). New-York: Oxford University Press.

Buffardi, L. (1971). Factors affecting the filled-duration illusion in the auditory, tactual, and visual modalities. Perception \& Psychophysics, 10, 292-294.

Buhusi, C. V., \& Meck, W. H. (2005). What makes us tick? Functional and neural mechanisms of interval timing. Nature Reviews Neuroscience, 6, 755-765. doi:10.1038/nrn1764

Burle, B., \& Casini, L. (2001). Dissociation between activation and attention effects in time estimation: Implications for internal clock models. Journal of Experimental Psychology. Human Perception and Performance, 27, 195-205. doi:10.1037/0096-1523.27.1.195

Casini, L., \& Macar, F. (1997). Effects of attention manipulation on judgments of duration and of intensity in the visual modality. Memory and Cognition, 25, 812-818.

Champagne, J., \& Fortin, C. (2008). Attention sharing during timing: Modulation by processing demands of an expected stimulus. Perception \& Psychophysics, 70, 630-639. doi:10.3758/PP.70.4.630

Church, R. M. (1984). Properties of the internal clock. Annals of the New York Academy of Sciences, 423, 566-582. doi:10.1111/ j.1749-6632.1984.tb23459.x

Church, R. M. (1997). Timing and temporal search time and behaviour: Psychological and neurobehavioural analyses (pp. 41-78). Amsterdam, Netherlands: North-Holland/Elsevier Science Publishers. doi:10.1016/S0166-4115(97)80054-4

Crystal, J. D. (2003). Nonlinearities in sensitivity to time: Implications for oscillator-based representations of interval and circadian clocks. In W. H. Meck (Ed.), Functional and neural mechanisms of interval timing (pp. 61-75). Boca Raton, FL, US: CRC Press.

Fetterman, J. G., \& Killeen, P. R. (1990). A componential analysis of pacemaker-counter timing systems. Journal of Experimental Psychology. Human Perception and Performance, 16, 766-780. doi:10.1037/0096-1523.16.4.766

Field, D. T., \& Groeger, J. A. (2004). Temporal interval production and short-term memory. Perception \& Psychophysics, 66, 808-819.
Fortin, C. (2003). Attentional time-sharing in interval timing. In W. H. Meck (Ed.), Functional and neural mechanisms of interval timing (pp. 235-260). Boca Raton, FL, US: CRC Press.

Fortin, C., Bédard, M.-C., \& Champagne, J. (2005). Timing during interruptions in timing. Journal of Experimental Psychology. Human Perception and Performance, 31, 276-288. doi:10.1037/ 0096-1523.31.2.276

Fortin, C., Champagne, J., \& Poirier, M. (2007). Temporal order in memory and interval timing: An interference analysis. Acta Psychologica, 126, 18-33. doi:10.1016/j.actpsy.2006.10.002

Fortin, C., \& Couture, E. (2002). Short-term memory and time estimation: Beyond the 2-second "critical" value. Canadian Journal of Experimental Psychology, 56, 120-127. doi:10.1037/h0087390

Fortin, C., Fairhurst, S., Malapani, C., Morin, C., Towey, J., \& Meck, W. H. (2009). Expectancy in humans in multisecond peak-interval timing with gaps. Attention, Perception, \& Psychophysics, 71, 789-802. doi:10.3758/APP.71.4.789

Fortin, C., \& Massé, N. (2000). Expecting a break in time estimation: Attentional time-sharing without concurrent processing. Journal of Experimental Psychology. Human Perception and Performance, 26, 1788-1796. doi:10.1037/0096-1523.26.6.1788

Fortin, C., \& Rousseau, R. (1998). Interference from short-term memory processing on encoding and reproducing brief durations. Psychological Research/Psychologische Forschung, 61, 269276. doi:10.1007/s004260050031

Fortin, C., \& Tremblay, S. (2006). Interrupting timing in interval production and discrimination: Similarities and differences. Behavioural Processes, 71, 336-343. doi:10.1016/j.beproc.2005.10.003

Fraisse, P. (1963). The psychology of time. Oxford, England: Harper \& Row.

Fraisse, P. (1984). Perception and estimation of time. Annual Review of Psychology, 35, 1-36. doi:10.1146/annurev.ps.35.020184.000245

Gaudreault, R., Fortin, C., \& Macar, F. (2010). Contrasting effects of interference and of breaks in interval timing. Acta Psychologica, 133, 3-16. doi:10.1016/j.actpsy.2009.07.013

Getty, D. J. (1975). Discrimination of short temporal intervals: A comparison of two models. Perception \& Psychophysics, 18, 1-8.

Getty, D. J. (1976). Counting processes in human timing. Perception \& Psychophysics, 20, 191-197.

Gibbon, J. (1977). Scalar expectancy theory and Weber's law in animal timing. Psychological Review, 84, 279-325. doi:10.1037/0033295X.84.3.279

Gibbon, J. (1991). Origins of scalar timing. Learning and Motivation, 22, 3-38. doi:10.1016/0023-9690(91)90015-Z

Gibbon, J., Church, R. M., \& Meck, W. H. (1984). Scalar timing in memory. Annals of the New York Academy of Sciences, 423, 5277. doi:10.1111/j.1749-6632.1984.tb23417.x

Gilliland, A. R., \& Martin, R. (1940). Some factors in estimating short time intervals. Journal of Experimental Psychology, 27, 243-255. doi:10.1037/h0060494

Grondin, S. (1992). Production of time intervals from segmented and nonsegmented inputs. Perception \& Psychophysics, 52, 345-350.

Grondin, S. (2001). From physical time to the first and second moments of psychological time. Psychological Bulletin, 127, 22-44. doi:10.1037/0033-2909.127.1.22

Grondin, S., Meilleur Wells, G., \& Lachance, R. (1999). When to start explicit counting in a time-intervals discrimination task: A Critical point in the timing process of humans. Journal of Experimental Psychology. Human Perception and Performance, 25, 993-1004. doi:10.1037/0096-1523.25.4.993

Grondin, S., Ouellet, B., \& Roussel, M.-E. (2004). Benefits and limits of explicit counting for discriminating temporal intervals. Canadian Journal of Experimental Psychology, 58, 1-12. doi:10.1037/h0087436

Hemmes, N. S., Brown, B. L., \& Kladopoulos, C. N. (2004). Time perception with and without a concurrent nontemporal task. Perception \& Psychophysics, 66, 328-341. 
Hicks, R. E., \& Allen, D. A. (1979). Counting eliminates the repetition effect in judgments of temporal duration. Acta Psychologica, 43, 361-366. doi:10.1016/0001-6918(79)90030-1

Hicks, R. E., Miller, G. W., \& Kinsbourne, M. (1976). Prospective and retrospective judgments of time as a function of amount of information processed. The American Journal of Psychology, 89, 719730. doi: $10.2307 / 1421469$

Hinton, S. C., Harrington, D. L., Binder, J. R., Durgerian, S., \& Rao, S. M. (2004). Neural systems supporting timing and chronometric counting: An FMRI study. Cognitive Brain Research, 21, 183192. doi:10.1016/j.cogbrainres.2004.04.009

Hinton, S. C., \& Rao, S. M. (2004). "One-thousand one...one-thousand two...": Chronometric counting violates the scalar property in interval timing. Psychonomic Bulletin \& Review, 11, 24-30.

Killeen, P. R. (1992). Counting the minutes. In F. Macar, V. Pouthas, \& W. J. Friedman (Eds.), Time, action and cognition: Towards bridging the gap (pp. 203-214). New York, NY, US: Kluwer Academic/Plenum Publishers.

Killeen, P. R., \& Weiss, N. A. (1987). Optimal timing and the Weber function. Psychological Review, 94, 455-468. doi:10.1037/0033295X.94.4.455

Kladopoulos, C. N., Brown, B. L., Hemmes, N. S., \& Cabeza de Vaca, S. (1998). The start-stop procedure: Estimation of temporal intervals by human subjects. Perception \& Psychophysics, 60, 438-450.

Kladopoulos, C. N., Hemmes, N. S., \& Brown, B. L. (2004). Prospective timing under dual-task paradigms: Attentional and contextual-change mechanisms. Behavioural Processes, 67, 221-233. doi:10.1016/j.beproc.2003.12.004

Lejeune, H. (1998). Switching or gating? The attentional challenge in cognitive models of psychological time. Behavioural Processes, 44, 127-145. doi:10.1016/S0376-6357(98)00045-X

Lejeune, H. (2000). Prospective timing, attention and the switch: A response to "gating or switching? Gating is a better model of prospective timing" by Zakay. Behavioural Processes, 52, 7176. doi:10.1016/S0376-6357(00)00136-4

Lejeune, H., \& Wearden, J. H. (2009). Vierordt's the experimental study of the time sense (1868) and its legacy. European Journal of Cognitive Psychology, 21, 941-960. doi:10.1080/09541440802453006

Lewis, P. A., \& Miall, R. C. (2003). Overview: An image of human neural timing. In W. H. Meck (Ed.), Functional and neural mechanisms of interval timing (pp. 515-532). Boca Raton, FL, US: CRC Press.

Macar, F. (2002). Expectancy, controlled attention and automatic attention in prospective temporal judgments. Acta Psychologica, 111, 243-262. doi:10.1016/S0001-6918(02)00052-5

Macar, F., Grondin, S., \& Casini, L. (1994). Controlled attention sharing influences time estimation. Memory and Cognition, 22, 673-686.

Meck, W. H. (1984). Attentional bias between modalities: Effect on the internal clock, memory, and decision stages used in animal time discrimination. Annals of the New York Academy of Sciences, 423, 528-541. doi:10.1111/j.1749-6632.1984.tb23457.x

Meck, W. H. (1997). Application of a mode-control model of temporal integration to counting and timing behaviour. In C. M. Bradshaw \& E. Szabadi (Eds.), Time and behaviour: Psychological and neurobehavioural analyses (pp. 133-184). Amsterdam, Netherlands: North-Holland/Elsevier Science Publishers. doi:10.1016/S0166-4115(97)80056-8

Meck, W. H., \& Church, R. M. (1983). A mode control model of counting and timing processes. Journal of Experimental Psychology. Animal Behavior Processes, 9, 320-334. doi:10.1037/0097-7403.9.3.320

Meck, W. H., Church, R. M., \& Gibbon, J. (1985). Temporal integration in duration and number discrimination. Journal of Experimental Psychology. Animal Behavior Processes, 11, 591597. doi:10.1037/0097-7403.11.4.591

Michon, J. A. (1985). The compleat time experiencer. In J. A. Michon \& J. L. Jackson (Eds.), Time, mind, and behavior (pp. 20-52). Berlin: Springer-Verlag.
Morey, R. D. (2008). Confidence intervals from normalized data: A correction to Cousineau (2005). Tutorials in Quantitative Methods for Psychology, 4, 61-64.

Penney, T. B., \& Vaitilingam, L. (2008). Imaging time. In S. Grondin (Ed.), Psychology of time (pp. 261-294). Bingley, UK: Emerald.

Petrusic, W. M. (1984). Explicit counting and time-order errors in duration discrimination. Annals of the New York Academy of Sciences, 423, 630-633. doi:10.1111/j.1749-6632.1984.tb23477.x

Petrusic, W. M. (2002). Chronometric mental counting in duration discrimination. In J. A. Da Silva \& N. P. Ribeiro-Filho (Eds.), Fechner day 2002. Proceedings of the Eighteenth Annual Meeting of the International Society for Psychophysics (pp. 116-122). Rio de Janeiro, Brazil: The International Society for Psychophysics.

Rakitin, B. C. (2005). The effects of spatial stimulus-response compatibility on choice time production accuracy and variability. Journal of Experimental Psychology. Human Perception and Performance, 31, 685-702. doi:10.1037/0096-1523.31.4.685

Rakitin, B. C., Gibbon, J., Penney, T. B., Malapani, C., Hinton, S. C., \& Meck, W. H. (1998). Scalar expectancy theory and peakinterval timing in humans. Journal of Experimental Psychology. Animal Behavior Processes, 24, 15-33. doi:10.1037/00977403.24.1.15

Rammsayer, T. H., \& Lima, S. D. (1991). Duration discrimination of filled and empty auditory intervals: Cognitive and perceptual factors. Perception \& Psychophysics, 50, 565-574.

Rammsayer, T., \& Ulrich, R. (2005). No evidence for qualitative differences in the processing of short and long temporal intervals. Acta Psychologica, 120, 141-171. doi:10.1016/j.actpsy.2005.03.005

Rattat, A.-C., \& Droit-Volet, S. (2012). What is the best and esiest method of preventing counting in different temporal task? Behavior Research Methods, 44, 67-80. doi:10.3758/s13428011-0135-3

Rousseau, R., Picard, D., \& Pitre, E. (1984). An adaptive counter model for time estimation. Annals of the New York Academy of Sciences, 423, 639-642. doi:10.1111/j.1749-6632.1984.tb23479.x

Thomas, E. A., \& Weaver, W. B. (1975). Cognitive processing and time perception. Perception \& Psychophysics, 17, 363367.

Tremblay, S., \& Fortin, C. (2003). Break expectancy in duration discrimination. Journal of Experimental Psychology. Human Perception and Performance, 29, 823-831. doi:10.1037/00961523.29.4.823

Wearden, J. H. (1991). Do humans possess an internal clock with scalar timing properties? Learning and Motivation. Special Issue: Animal timing, 22, 59-83. doi:10.1016/0023-9690(91)90017-3

Wearden, J. H., Denovan, L., Fakhri, M., \& Haworth, R. (1997). Scalar timing in temporal generalization in humans with longer stimulus durations. Journal of Experimental Psychology. Animal Behavior Processes, 23, 502-511. doi:10.1037/0097-7403.23.4.502

Wearden, J. H., \& Lejeune, H. (2008). Scalar properties in human timing: Conformity and violations. The Quarterly Journal of Experimental Psychology, 61, 569-587. doi:10.1080/ 17470210701282576

Wearden, J. H., \& McShane, B. (1988). Interval production as an analogue of the peak procedure: Evidence for similarity of human and animal timing processes. The Quarterly Journal of Experimental Psychology B: Comparative and Physiological Psychology, 40, 363-375.

Woodrow, H. (1930). The reproduction of temporal intervals. Journal of Experimental Psychology, 13, 473-499. doi:10.1037/h0070462

Woodrow, H. (1934). The temporal indifference interval determined by the method of mean error. Journal of Experimental Psychology, 17, 167-188. 
Zakay, D. (1990). The evasive art of subjective time measurement: Some methodological dilemmas. In R. A. Block (Ed.), Cognitive models of psychological time (pp. 59-84). Hillsdale, NJ, England: Lawrence Erlbaum Associates, Inc.

Zakay, D., \& Block, R. A. (1996). The role of attention in time estimation processes. In M. A. Pastor \& J. Artieda (Eds.), Time, internal clocks and movement. Advances in psychology (Vol. 115, pp. 143-164). Amsterdam, Netherlands: North-Holland/Elsevier Science Publishers, xiv, $310 \mathrm{pp}$.

Zakay, D., Nitzan, D., \& Glicksohn, J. (1983). The influence of task difficulty and external tempo on subjective time estimation. Perception \& Psychophysics, 34, 451-456. 